\title{
The impact of senior citizens' use of online social networks on their cognitive function
}

\author{
Kim, Hak Joon \\ Southern Connecticut State University, USA (kimh1@ southernct.edu)
}

Kim, Joan

Cornell University, USA (jk2355@cornell.edu)

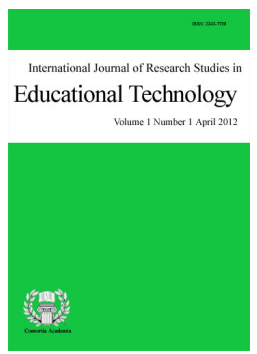

ISSN: $2243-7738$ Online ISSN: 2243-7746 DOI: $10.5861 /$ ijrset.2014.844

\section{Abstract}

The primary purpose of the study was to examine whether senior citizens' use of online social networks affect their cognitive function. For this study, 213 senior citizens who are at least 60 years of age and do not have pre-diagnosed Alzheimer's disease (AD) were randomly selected from a variety of local communities such as a non-AD-patient-retirement home. To measure the cognitive function levels of the selected senior citizens, the Mini Mental State Exam (MMSE), which is the most widely used standardized cognitive screening test, was administered to each participant. The results of the study show that seniors' use of online social networks positively affected their cognitive function levels. Senior citizens who use online social networks had a significantly higher cognitive function level than those who do not use online social networks. In addition, the results show that there was a significant relationship between the number of months for seniors' use of online social networks and their MMSE scores. Seniors received higher MMSE scores as they use online social networks longer. The results of the study suggest that seniors' participation in online social networking, which can be cognitively stimulating, is associated with maintenance or even improvement of their cognitive functions and seems to protect against age-related decline of cognitive functions.

Keywords: social networking; older adults; cognitive aging; internet use; cognition 


\section{The impact of senior citizens' use of online social networks on their cognitive function}

\section{Introduction}

Alzheimer's disease (AD), the most common form of dementia, is a chronic debilitating neurological condition causing gradual but unalterable cognitive and functional decline (Thies \& Bleiler, 2013). AD is the sixth leading cause of death in the United States and is the fifth leading cause of death in Americans age 65 years or older. It was estimated that in 2013 there were 5.2 million Americans with AD, but by 2050 that number is projected to increase to 13.8 million (Thies \& Bleiler, 2013). One in nine people age 65 and older (11\%) has AD and about one-third of people age 85 and older (32\%) have AD. The financial burden it imposes on patients and their families is tremendous as well. Total payments in 2013 for health care, long-term care, and hospice services for people age 65 years and older with dementia were \$203 billion (not including the contributions of unpaid caregivers) (Thies \& Bleiler, 2013). As the number of older people increases rapidly, more and more people will face the threat of AD.

While elderly people worry about losing their memories, cognitive functions, and eventually their lives because of $\mathrm{AD}$, over the last decades numerous researchers have been actively searching for ways to prevent and treat AD, or to at least delay the onset (Andrade \& Radhakrishnan, 2009). Many factors would contribute to one's likelihood of developing AD. The most robust risk factor for AD is advancing age, which cannot be halted.

Among many previous research studies that have been done to discover effective AD prevention methods, some studies have focused on social and leisure activities that involve mental activity and social interactions, concluding that participation in social and leisure activities has been associated with a lower risk of dementia (Fabrigoule et al., 1995; Wang, Karp, Winblad, \& Fratiglioni, 2002; Verghese et al., 2003; Fratiglioni, Paillard-Borg, \& Winblad, 2004; Karp et al., 2005; Saczynski et al., 2006; Krueger et al., 2009; Verghese, Wang, Katz, Sanders, \& Lipton, 2009; Sharp, Reynolds, Pedersen, \& Gatz, 2010; Wang, Xu, \& Pei, 2012). The odds of developing $\mathrm{AD}$ were shown to be lower among those who more often participated in activities involving social interactions. The odds were shown to be even lower for those who more frequently participated in novelty-seeking activities (Stern et al., 1994; Evans et al., 1997; Wilson et al., 2002; Fritsch, Smyth, Debanne, Petot, \& Friedland, 2005; McDowell, Xi, Lindsay, \& Tierney, 2007; Hall et al., 2009; Eckroth-Bucher \& Siberski, 2009). Given recent evidence from studies suggesting that mental activity protects against cognitive function decline and clinical manifestations of dementia in aging, increased emphasis should be placed on providing programs and activities that offer opportunities to read, think, discuss, interact socially and learn new things to elderly people.

So far many previous studies have focused on social and leisure activities that require direct in-person social interactions (Fabrigoule et al., 1995; Lubben \& Gironda, 1996; Wang, Karp, Winblad, \& Fratiglioni, 2002; Karp et al., 2005; Saczynski et al., 2006; Winningham \& Pike, 2007; Krueger et al., 2009; Wang, Xu, \& Pei, 2012). However, there has been little research pertaining to senior citizens' online social interactions through online social networks and the novelty-seeking learning of online social networking through computers and its impact on their cognitive function.

Malone (2004) argues that, thanks to digital and Internet technologies, the communication costs of human interaction has decreased exponentially and thus has enabled instant connectivity despite growing populations and broader geospatial ranges between people. Online social media has decentralized communication by allowing each individual to be not only an information consumer but a producer as well (Hand \& Ching, 2011). Online social media technologies have also allowed for the creation of complex and dynamic social networks, the scale of which has never been seen before.

Senior citizens are the fastest growing computer and Internet user group (Eastman \& Iyer, 2005; Wagner, 
The impact of senior citizens' use of online social networks on their cognitive function

Hassanein, \& Head, 2010). According to newly released data from the Pew Research Center (Smith, 2014), 59\% of seniors (defined as those ages 65 or older) use the Internet and $46 \%$ of the Internet using seniors use online social networks. Online social networks have permeated all generations of Internet users, becoming a prominent communications tool. Today, there are hundreds of different online social networks that Internet users are able to choose from. Of those various networks, some such as Facebook, LinkedIn, MySpace, and Twitter have gained much popularity.

Online social networks allow for easy access, comfortably from home. Many online social web sites are free and available to everyone. The online social networks are also extremely large, encouraging users to make new acquaintances, find old friends, and stay in touch with as many people as desired. Finally, online social networking allows users to transfer information to one another, giving them boundless resources of knowledge. Online social networking requires users to read, think, discuss, interact socially, and learn new things all at once (Slegers, van Boxtel, \& Jolles, 2012).

Only a very limited number of computer and Internet use studies have actually focused on the impact of older adults' computer and Internet use on their cognitive function as the primary outcome. McConatha, McConatha, and Dermigny's study (1994) showed that, in a small sample ( $\mathrm{N}=14)$ of long-term care residents aged between 59 and 89, the Mini Mental State Exam (MMSE) score improved after using computer and Internet services for 6 months. Comparable results were found in a subsequent study, where 29 nursing home residents, aged 50 and older, were divided into a computer training group and a control group (McConatha, McConatha, Deaner, \& Dermigny, 1995). After 6 months of using the computer and Internet services, participants in the computer-training group improved on their MMSE scores, while the control group remained unchanged. The results of the studies indicate that learning to use a computer and the Internet in later life may have beneficial effects on the cognitive ability of elderly people.

Conflicting results have been found in a few other studies on whether elderly people's computer and Internet use affects their cognitive functions. Slegers, van Boxtel, and Jolles (2009) studied the impact of computer and Internet use on cognitive function in a randomized controlled study over a 12-month period. Participants in the age between 65 and 75 years, who were randomly assigned to an intervention group, were compared with three control groups to account for effects of intervention. No effects of computer training and habitual use in daily life were found on several domains of cognitive abilities. In a following bigger study, Slegers, van Boxtel, and Jolles (2012) investigated the relationship between computer use and changes in cognitive function over a 6-year period in both younger (24-49 years) and older adults (older than 50 years). They used data that were obtained from a study into cognitive aging: the Maastricht Aging Study, involving 1823 normal aging adults who were followed for 9 years (Jolles, Houx, van Boxtel, \& Ponds, 1995).

Regarding the relationship between computer use and changes in cognitive abilities, a small protective effect of computer use on selective attention and memory processes was found in both younger and older adults. Because this effect was too small, however, they concluded that promoting computer use to support cognitive functions might not be an efficient intervention strategy. Since the results of these previous studies, which examined the impact of seniors' computer and Internet use on their cognitive function, are inconsistent and little research has been done particularly on seniors' use of online social networks, it would be even more important to investigate whether senior citizens' use of online social networks has impact on their cognitive function.

\section{Methods}

In this study, an online social network will be defined as a web-based service that allows individuals to construct some sort of a public profile within a bounded system, articulate a list of other users with whom they share a connection, and communicate thoughts, information, and various forms of media to online "friends," old and new. For this study, 213 senior citizens who are at least 60 years of age and do not have pre-diagnosed AD were selected from a variety of local communities such as a local church, a non-AD-patient-retirement home, 
Kim, H. J. \& Kim, J.

and a senior club at a local community center.

In order to measure the cognitive function levels of the selected senior citizens, the Mini Mental State Exam (MMSE), which is the most widely used standardized cognitive screening test, was administered to each participant. MMSE scores can range from 0 to 30; a score of less than 24 indicates global cognitive impairment with individuals having at least 8 years of education. Usually, a score between 23 and 18 indicates mild cognitive impairment. Scores below 17 indicate moderate cognitive impairment and scores of 10 or less are indicative of severe cognitive impairment (Folstein, Folstein, McHugh, \& Fanjiang, 2001). In addition, participants' age, gender, race, and the length of the use of online social networks were surveyed to investigate the relationships between these variables and their MMSE scores. Finally, senior citizens who did not use online social networks were also asked why they did not use them.

\section{Results and Discussion}

As seen in Table 1, the majority (55.4\%) of the senior citizens did not use online social networks. Only about $45 \%$ of the seniors used online social networks. With regard to the use of online social networks, the results show that there is a digital divide even among seniors. This finding is consistent with previous studies reporting America's seniors continue to lag behind younger Americans when it comes to tech adoption and use (Selwyn, Gorard, Furlong, \& Madden, 2003; Carpenter \& Buday, 2007; Smith, 2014).

About $48 \%$ of the male seniors used online social networks while almost $42 \%$ of the female seniors used online social networks (see Table 1). Nearly $6 \%$ more male seniors used online social networks than female seniors. Female seniors tend to be underrepresented on online social networks. The results of the study generally support the findings of previous studies reporting that there is a gender gap among seniors in using the Internet (Irizarry \& Downing, 1997; Karavidas, Lim, \& Katsiks, 2005; Slegers, van Boxtel, \& Jolles, 2012; Smith, 2014). A chi-square analysis, $\chi^{2}(1, \mathrm{~N}=213)=.713, p=.398$, however, revealed that there was no statistically significant gender difference in seniors' use of online social networks.

\section{Table 1}

Gender differences in seniors' use of online social networks

\begin{tabular}{lccr}
\hline \multirow{2}{*}{ Use of Social Networks } & \multicolumn{2}{c}{ Gender } & \multirow{2}{*}{ Total } \\
\cline { 2 - 3 } & Male & Female & \\
\hline Users & $49(47.6 \%)$ & $46(41.8 \%)$ & $95(44.6 \%)$ \\
Non-Users & $54(52.4 \%)$ & $64(58.2 \%)$ & $118(55.4 \%)$ \\
Total & $\mathbf{1 0 3 ( 1 0 0 \% )}$ & $\mathbf{1 1 0 ( 1 0 0 \% )}$ & $\mathbf{2 1 3 ( 1 0 0 \% )}$ \\
\hline
\end{tabular}

Table 2 shows the differences in seniors' use of online social networks by race. White seniors' use (44.2\%) of online social networks was in line with the expectation $(44.6 \%)$. While none $(0 \%)$ of the four surveyed Hispanic seniors and only three (15\%) of the 20 surveyed Black seniors used online social networks respectively, $35(58.3 \%)$ of the 60 surveyed Asian seniors used online social networks. A chi-square analysis, $\chi^{2}(3, N=213)$ $=14.901, p=.002$, indicated that there was a statistically significant difference in seniors' use of online social networks by race. Unlike other minority group seniors who were seriously underrepresented on online social networks, Asian seniors were fairly overrepresented on online social networks. It has to be noted here, however, that the sample sizes of the minority groups were relatively very small. Therefore, the significant finding of the study would be interpreted with caution. 
The impact of senior citizens' use of online social networks on their cognitive function

Table 2

Race differences in seniors' use of online social networks

\begin{tabular}{|c|c|c|c|c|c|}
\hline \multirow[t]{2}{*}{ Use of Social Networks } & \multicolumn{4}{|c|}{ Race } & \multirow[t]{2}{*}{ Total } \\
\hline & White & Black & Asian & Hispanic & \\
\hline Users & $57(44.2 \%)$ & $3(15 \%)$ & $35(58.3 \%)$ & $0(0 \%)$ & $95(44.6 \%)$ \\
\hline Expected Users & $57.5(44.6 \%)$ & $8.9(44.5 \%)$ & $26.8(44.7 \%)$ & $1.8(45 \%)$ & $95.0(44.6 \%)$ \\
\hline Non-Users & $72(55.8 \%)$ & $17(85 \%)$ & $25(41.7 \%)$ & $4(100 \%)$ & $118(55.4 \%)$ \\
\hline Expected Non-Users & $71.5(55.4 \%)$ & $11.1(55.5)$ & $33.2(55.3 \%)$ & $2.2(55 \%)$ & $118.0(55.4 \%)$ \\
\hline Total & $129(100 \%)$ & $20(100 \%)$ & $60(100 \%)$ & $4(100 \%)$ & $213(100 \%)$ \\
\hline
\end{tabular}

To examine whether or not age is an important factor that affects seniors' use of online social networks, age was compared between the users and non-users. There was virtually no difference between the average ages of the users and non-users (see Table 3). This finding is contrary to a number of previous broader studies reporting that older adults' computer and Internet use may be predicted by their age (Selwyn, Gorard, Furlong, \& Madden, 2003; Carpenter \& Buday, 2007; Slegers, van Boxtel, \& Jolles, 2012; Smith, 2014). According to Smith's recent survey $(2014$, p. 2), for example, Internet use among seniors fell off notably starting at approximately age 75 . About $68 \%$ of seniors in their early 70 s went online, but Internet adoption fell to $47 \%$ among 75-79 year olds. Therefore, the results of the study may be somewhat surprising. Because very little has been known about seniors' online social networking activities, it is difficult to explain possible reasons why seniors' age does not affect their use of online social networks. More research on how senior citizens adopt and use these new online social media should be done to better understand this new online arena.

Table 3

Descriptive statistics for age by the use of social networks

\begin{tabular}{lccccc}
\hline \multicolumn{1}{c}{ Use of Social Networks } & $\mathrm{N}$ & Minimum & Maximum & Mean & SD \\
\hline Users & 95 & 60 & 80 & 66.71 & 4.35 \\
Non-Users & 118 & 60 & 92 & 66.56 & 5.50 \\
\hline
\end{tabular}

Table 4 reports descriptive statistics for MMSE scores by online social network users and non-users. Seniors who use online social networks have a greater average of cognitive function levels than seniors who do not use online social networks. The mean MMSE score for seniors who use online social networks is 27.69. In comparison, the mean MMSE score for those who do not use online social networks is 26.01. The mean MMSE score for the online social network users is approximately 1.7 points higher than the online social network non-users. An independent samples t-test showed that the cognitive function levels of the seniors who use online social networks were significantly higher than those of the seniors who do not use online social networks ( $t(211)$ $=7.653, p=.000)$. The results of the study suggest that engagement in online social networking is associated with maintenance or even improvement of cognitive functions and seems to protect against age-related decline of cognitive functions. This finding further supports previous broader studies reporting that learning to use a computer and the Internet in later life may have beneficial effects on the cognitive abilities of elderly people (McConatha, McConatha, \& Dermigny, 1994; McConatha, McConatha, Deaner, \& Dermigny, 1995).

Table 4

Descriptive statistics for MMSE scores by social network users and non-users

\begin{tabular}{lccccc}
\hline \multicolumn{1}{c}{ Use of Social Networks } & $\mathrm{N}$ & Minimum & Maximum & Mean & SD \\
\hline Users & 95 & 25 & 30 & 27.69 & 1.46 \\
Non-Users & 118 & 22 & 30 & 26.01 & 1.70 \\
\hline
\end{tabular}


Kim, H. J. \& Kim, J.

Table 5 shows descriptive statistics for the age and MMSE score of the seniors. The minimum and maximum ages of the seniors were 60 and 92 respectively. The mean age was almost 67 . The minimum and maximum MMSE scores that they received were 22 and 30 points respectively. The mean MMSE score was almost 27 points. A paired-samples t-test indicated that there was a significant negative relationship between the age of the seniors and their MMSE scores $(\mathrm{t}(212)=94.72, p=.000)$. As seniors get older, their MMSE scores tend to get lower $\left(\mathrm{r}(211)=-.52, p<.01, \mathrm{r}^{2}=-.27\right)$. Since cognitive decline is one of the consequences of aging (Craik \& Salthouse, 2000; Eckroth-Bucher \& Siberski, 2009), it would not be surprising to see the finding of this study that reconfirms it.

Table 5

Descriptive statistics for age and MMSE score

\begin{tabular}{lccccc}
\hline & $\mathrm{N}$ & Minimum & Maximum & Mean & SD \\
\hline Age & 213 & 60 & 92 & 66.62 & 5.01 \\
MMSE & 213 & 22 & 30 & 26.76 & 1.80 \\
\hline
\end{tabular}

As seen in Table 6, the minimum and maximum numbers of months for the use of online social networks were 0 and 36 respectively. The mean number of months was about 7 months. In order to investigate whether or not the number of months for the use of online social networks has an effect on seniors' MMSE scores, MMSE scores were compared by the number of months. A paired-samples t-test indicated that there was a significant relationship between the number of months for the use of online social networks and the MMSE $\operatorname{score}(\mathrm{t}(212)=-$ 31.16, $p=.000)$. As seniors use online social networks longer, they tend to receive higher MMSE scores (r(211) $=.48, p<.01, \mathrm{r}^{2}=.23$ ). This finding is generally in line with the results of previous broader studies (McConatha, McConatha, \& Dermigny, 1994; McConatha, McConatha, Deaner, \& Dermigny, 1995), which reported positive effects of long-term computer and Internet use on cognitive changes.

Table 6

Descriptive statistics for the number of months for use and MMSE score

\begin{tabular}{lccccc}
\hline & $\mathrm{N}$ & Minimum & Maximum & Mean & SD \\
\hline Number of Months for Use & 213 & 0 & 36 & 7.15 & 9.92 \\
MMSE Score & 213 & 22 & 30 & 26.76 & 1.80 \\
\hline
\end{tabular}

Table 7 shows that overall male seniors earned higher MMSE scores than did female seniors. Male seniors received average score of 27.23 while female seniors received average score of 26.32. The average MMSE score for male seniors was approximately 1 point higher than female seniors. An independent samples t-test showed that the MMSE scores for male seniors were significantly higher than the ones for female seniors $(\mathrm{t}(211)=3.818, p$ $=.000$ ). Because the results of the present study have already reported that the mean MMSE score for the online social network users was significantly higher than the online social network non-users (see Table 4) and that more male seniors used online social networks than female seniors (see Table 1), this finding would be in line with our expectation.

Table 7

Descriptive statistics for MMSE score by gender

\begin{tabular}{|c|c|c|c|c|c|}
\hline Gender & $\mathrm{N}$ & Minimum & Maximum & Mean & SD \\
\hline Male & 103 & 23 & 30 & 27.23 & 1.73 \\
\hline Female & 110 & 22 & 30 & 26.32 & 1.77 \\
\hline
\end{tabular}

Table 8 summarizes reasons why seniors do not use online social networks. There were a variety of issues that impact seniors' non-use of online social networks. Their answers to the question as to why they do not use 
The impact of senior citizens' use of online social networks on their cognitive function

online social networks could be largely classified into two broad categories (see Table 8 ). Nearly $47 \%$ of the surveyed non-users answered that they simply do not want to use online social networks because of no interest in online social networking, refusal to learn something new, a visual deficit, arthritis interfering with typing, and so on.

On the other hand, about $53 \%$ of the non-users still wanted to use online social networks, but they did not have resources for using computers and online social networks. Those seniors were basically further classified into two sub-groups: (1) I do not know how to use computers and/or online social networks (33.1\%) and (2) I do not own a computer with an Internet connection (20.3\%). The results of the study clearly show that resources continue to be a major barrier for seniors who do not have a computer and/or computer literacy. The government needs some kind of intervention to help seniors get online, especially those with low income and limited education. There should be a strong collaborative partnership with industry, the nonprofit sector, and government to make sure everyone in this nation, regardless of age or income, is able to reap the benefits from access to affordable computer, Internet, and educational program.

Table 8

Reasons why seniors do not use online social networks

\begin{tabular}{|c|c|c|c|c|}
\hline & \multicolumn{3}{|c|}{ Reasons } & \multirow[t]{7}{*}{ Total } \\
\hline & \multirow{6}{*}{$\begin{array}{l}\text { Do not want to use them because } \\
\text { of no interest and/or functional } \\
\text { impairments such as visual } \\
\text { deficits. }\end{array}$} & \multicolumn{2}{|c|}{$\begin{array}{l}\text { Want to use them, but do not } \\
\text { have resources. }\end{array}$} & \\
\hline & & $\begin{array}{l}\text { Do not know } \\
\text { how to use }\end{array}$ & $\begin{array}{l}\text { Do not own a } \\
\text { computer with }\end{array}$ & \\
\hline & & computers & an Internet & \\
\hline & & and/or online & connection. & \\
\hline & & social & & \\
\hline & & networks. & & \\
\hline Non-Users & $55(46.6 \%)$ & $39(33.1 \%)$ & $24(20.3 \%)$ & $118(100 \%)$ \\
\hline Total & $55(46.6 \%)$ & $63(53.4 \%)$ & & $118(100 \%)$ \\
\hline
\end{tabular}

\section{Conclusions}

The primary purpose of the present study was to examine whether senior citizens' use of online social networks affect their cognitive function. The results of the study show that seniors' use of online social networks positively affected their cognitive function levels. Senior citizens who use online social networks had a significantly higher cognitive function level than those who do not use online social networks. In addition, the results show that there was a significant relationship between the number of months for seniors' use of online social networks and their MMSE scores. Seniors received higher MMSE scores as they use online social networks longer. The results of the study suggest that seniors' participation in online social networking, which can be cognitively stimulating, is associated with maintenance or even improvement of their cognitive functions and seems to protect against age-related decline of cognitive functions. Therefore, seniors' use of online social networks may be an efficient and effective method of delaying and preventing AD.

However, the results of the study also show that the majority (55.4\%) of senior citizens did not use online social networks. Although over $53 \%$ of the non-users still wanted to use online social networks, they could not use them because they did not have resources for using online social networks. There is a digital divide even among seniors who still remain far behind all adult Internet users.

\subsection{Educational Implications}

These findings have strong implications for public libraries, academic programs, and mental health 
organizations. The results of the study suggest that states and local communities promote seniors' use of online social networks for their mental health. Some senior citizens were "voluntary non-users" because they really had no interest in online social networking. However, the majority of the non-users could not use online social networks because they did not have resources for using computers and online social networks although they wanted to use them. Therefore, they should also provide senior citizens with an access to computers with an Internet connection and education programs and activities that offer opportunities for seniors to learn how to use online social networks.

Public libraries have the potential to be an ideal place for providing both an access to computers with an Internet connection and education programs and activities for senior citizens including those who are socially and economically disadvantaged to learn how to use online social networks (Xie \& Bugg, 2009). However, to date most public libraries simply provide access to computers and the Internet, primarily due to lack of sufficient staff to provide computer training for patrons (Bertot, Jaeger, McClure, \& Ryan, 2006). An innovative program, which involves strategic and productive collaboration among public libraries, senior centers, academic programs at a university, the National Institute on Aging (NIA), and the National Institutes of Health (NIH), can provide a valuable new approach to improve the computer access and literacy and the mental health of the rapidly aging population (Xie \& Bugg, 2009).

\subsection{Limitations}

A few methodological limitations of the present study should be mentioned. First, the study included a small sample. In addition, it was a convenience sample. The 213 subjects in the study were all from the New Haven County area in Connecticut, due to their convenient availability. The median household income in the New Haven County is $\$ 62,234$ a year (United States Census Bureau, 2014). That number is approximately $\$ 11,000$ higher than the national median household income (Noss, 2013). As the sample only represents an upper-middle class area, therefore, the findings are only preliminary and do not allow generalization to the population.

Socio-economic status and education level could also be important variables that affect seniors' use of online social networks. People who have had less income and have less education would be less likely to have had much opportunity for computer access and literacy. In the study, however, these two important variables were not included. Therefore, it should also be considered a limitation of the study.

The greatest limitation to the study would be that the study itself was a cross-sectional study. An association between usage of online social networks and cognitive function levels was found. The data from this cross-sectional study represent a captured moment in time in which there is a positive relationship between seniors' use of online social networks and their cognitive function levels. However, this does not establish causation. While it is assumed that online social network usage causes higher cognitive function levels, the causation might be the other way around in which the high levels of cognitive function cause online social network usage. In order to find out which is the causation of this association, the researchers could conduct a longitudinal study that uses experimental research designs.

\section{References}

Andrade, C., \& Radhakrishnan, R. (2009). The prevention and treatment of cognitive decline and dementia: An overview of recent research on experimental treatments. Indian Journal of Psychiatry, 51(1), 12-25. http://dx.doi.org/10.4103/0019-5545.44900

Bertot, J. C., Jaeger, P. T., McClure, C. R., \& Ryan, J. (2006). Public libraries and the Internet 2006: Survey results and findings for the Bill \& Melinda Gates Foundation and the American Library Association. Tallahassee, FL: Information Institute.

Carpenter, B. D., \& Buday, S. (2007). Computer use among older adults in a naturally occurring retirement community. Computers in Human Behavior, 23, 3012-3024. 
The impact of senior citizens' use of online social networks on their cognitive function

http://dx.doi.org/10.1016/j.chb.2006.08.015

Craik, F. I. M., \& Salthouse, T. A. (2000). The handbook of aging and cognition (2nd ed.). Mahwah, NJ: Erlbaum.

Dickinson, A., \& Gregor, P. (2006). Computer use has no demonstrated impact on the well-being of older adults. International Journal of Human-Computer Studies, 64(8), 744-753. http://dx.doi.org/10.1016/j.ijhcs.2006.03.001

Eastman, J. K., \& Iyer, R. (2005). The impact of cognitive age on Internet use of the elderly: An introduction to the public policy implications. International Journal of Consumer Studies, 29(2), 125-136. http://dx.doi.org/10.1111/j.1470-6431.2004.00424.x

Eckroth-Bucher, M., \& Siberski, J. (2009). Preserving cognition through an integrated cognitive stimulation and training program. American Journal of Alzheimer's Disease and Other Dementias, 24(3), 234-245. http://dx.doi.org/10.1177/1533317509332624

Evans, D. A., Hebert, L. E., Beckett, L. A., Scherr, P. A., Albert, M. S., Chown M. J., et al. (1997). Education and other measures of socioeconomic status and risk of incident Alzheimer disease in a defined population of older persons. Archives of neurology, 54, 1399-1405. http://dx.doi.org/10.1001/archneur.1997.00550230066019

Fabrigoule, C., Letenneur, L., \& Dartigues, J. F., Zarrouk, M., Commenges, D., \& Barberger-Gateau, P. (1995) Social and leisure activities and risk of dementia: A prospective longitudinal study. Journal of the American Geriatrics Society, 43, 485-490.

Folstein, M. F., Folstein, S. E., McHugh, P. R., \& Fanjiang, G. (2001). Mini mental state examination user's guide. Odessa, FL: Psychological Assessment Resources, Inc.

Fratiglioni, L., Paillard-Borg, S., \& Winblad, B. (2004). An active and socially integrated lifestyle in late life might protect against dementia. Lancet Neurol, 3, 343-353. http://dx.doi.org/10.1016/S1474-4422(04)00767-7

Fritsch, T., Smyth, K. A., Debanne, S. M., Petot, G. J., \& Friedland, R. P. (2005). Participation in novelty-seeking leisure activities and Alzheimer's disease. Journal of Geriatric Psychiatry and Neurology, 18(3), 134-141. http://dx.doi.org/10.1177/0891988705277537

Jolles, J., Hous, P. J., van Boxtel, M. P. J., \& Ponds, R. (1995). Maastricht aging study: Determinants of cognitive aging. Maastricht, Netherland: Neuropsych Publishers.

Karavidas, M., Lim, N. K., \& Katsiks, S. L. (2005). The effects of computers on older adult users. Computers in Human Behavior 21, 697-711. http://dx.doi.org/10.1016/j.chb.2004.03.012

Karp, A., Paillard-Borg, S., Wang, H. X., Silverstein, M., Winblad, B., \& Fratiglioni, L. (2005). Mental, physical and social components in leisure activities equally contribute to decrease dementia risk. Dementia and Geriatric Cognitive Disorders, 21, 65-73. http://dx.doi.org/10.1159/000089919

Krueger, K. R., Wilson, R. S., Kamenetsky, J. M., Barnes, L. L., Bienias, J. L., \& Bennett, D. A. (2009). Social engagement and cognitive function in old age. Experimental Aging Research, 35, 45-60. http://dx.doi.org/10.1080/03610730802545028

Hall, C. B., Lipton, R. B., Sliwinski, M., Katz, M. J., Derby, C. A., \& Verghese, J. (2009). Cognitive activities delay onset of memory decline in persons who develop dementia. Neurology, 73, 356-361. http://dx.doi.org/10.1212/WNL.0b013e3181b04ae3

Hand, L. C., \& Ching, B. D. (2011). An exploration of power and citizen engagement in local governments' use of social media. Administrative Theory \& Praxis, 33(3), 362-382. http://dx.doi.org/10.2753/ATP1084-1806330303

Irizarry, C., \& Downing, A. (1997). Computers enhancing the lives of older people. Australian Journal on Ageing, 16(4), 161-165. http://dx.doi.org/10.1111/j.1741-6612.1997.tb01042.x

Lubben, J., \& Gironda, M. (1996). Assessing social support networks among older people in the United States. In H. Litwin (Ed.), The social networks of older people: A cross-national analysis. London: Praeger.

Malone, T. W. (2004). The future of work: How the new order of business will shape your organization, your management style and your life. Boston: Harvard Business Press.

McConatha, J. T., McConatha, D., Deaner, S. L., \& Dermigny, R. (1995). Computer based intervention for the 
Kim, H. J. \& Kim, J.

education and therapy of institutionalized older adults. Educational Gerontology, 21, 129-138. http://dx.doi.org/10.1080/0360127950210202

McConatha, D., McConatha, J. T., \& Dermigny, R. (1994). The use of computer services to enhance the quality of life for long term care residents. The Gerontologist, 34, 553-556. http://dx.doi.org/10.1093/geront/34.4.553

McDowell, I., Xi, G., Lindsay, J., \& Tierney, M. (2007). Mapping the connections between education and dementia. Journal of Clinical and Experimental Neuropsychology, 29, 127-141. http://dx.doi.org/10.1080/13803390600582420

Noss, A. (2013). Household Income: 2012. Retrieved from http://www.census.gov/prod/2013pubs/acsbr12-02.pdf

Saczynski, J. S., Pfeifer, L. A., Masaki, K., Korf, E. S., Laurin, D., White, L., et al. (2006). The effect of social engagement on incident dementia: the Honolulu-Asia Aging Study. American Journal of Epidemiology, 163, 433-440. http://dx.doi.org/10.1093/aje/kwj061

Sharp, E. S., Reynolds, C. A., Pedersen, N. L., \& Gatz, M. (2010). Cognitive engagement and cognitive aging: is openness protective? Psychology and Aging, 25, 60-73. http://dx.doi.org/10.1037/a0018748

Selwyn, N., Gorard, S., Furlong, J., \& Madden, L. (2003). Older adults' use of information technology in everyday life. Aging and Society, 23, 561-582. http://dx.doi.org/10.1017/S0144686X03001302

Slegers, K., van Boxtel, M., \& Jolles, J. (2012). Computer use in older adults: Determinants and the relationship with cognitive change over a 6 year episode. Computers in Human Behavior, 28, 1-10. http://dx.doi.org/10.1016/j.chb.2011.08.003

Smith, A. (2014). Older Adults and Technology Use. Washington, D.C.: Pew Research Center. Retrieved from http://www.pewinternet.org/files/2014/04/PIP_Seniors-and-Tech-Use_040314.pdf

Stern, Y., Gurland., B., Tatemichi, T. K., Tang, M. X., Wilder, D., \& Mayeux R. (1994). Influence of education and occupation on the incidence of Alzheimer's disease. Journal of the American Medical Association, 271, 1004-1010. http://dx.doi.org/10.1001/jama.1994.03510370056032

Thies, W., \& Bleiler, L. (2013). 2013 Alzheimer's disease facts and figures. Alzheimer's \& Dementia, 9(2), 208-245. http://dx.doi.org/10.1016/j.jalz.2013.02.003

United States Census Bureau. (2014). State \& County QuickFacts. Retrieved from http://quickfacts.census.gov/qfd/states/09/09009.html

Verghese, J. et al. (2003). Leisure activities and the risk of dementia in the elderly. The New England Journal of Medicine, 348, 2508-2516. http://dx.doi.org/10.1056/NEJMoa022252

Verghese, J., Wang, C., Katz, M. J., Sanders, A. \& Lipton, R. B. (2009). Leisure activities and risk of vascular cognitive impairment in older adults. Journal of Geriatric Psychiatry and Neurology, 22(2), 110-118. http://dx.doi.org/10.1177/0891988709332938

Wang, H. X., Karp, A., Winblad, B., \& Fratiglioni, L. (2002). Late-life engagement in social and leisure activities is associated with a decreased risk of dementia: a longitudinal study from the Kungsholmen Project. American Journal of Epidemiology, 155, 1081-1087. http://dx.doi.org/10.1093/aje/155.12.1081

Wagner, N., Hassanein, K., \& Head, M. (2010). Computer use by older adults: A multi-disciplinary review. Computers in Human Behavior, 26(5), 870-882. http://dx.doi.org/10.1016/j.chb.2010.03.029

Wang, H. X., Xu, W., \& Pei, J. J. (2012). Leisure activities, cognition and dementia. BBA Molecular Basis of Disease, 1822, 482-491. http://dx.doi.org/10.1016/j.bbadis.2011.09.002

Wilson, R. S., Mendes De Leon, C. F., Barnes, L. L., Schneider, J. A., Bienias, J. L., Evans, D. A., et al. (2002). Participation in cognitively stimulating activities and risk of incident Alzheimer disease. Journal of the American Medical Association, 287, 742-748. http://dx.doi.org/10.1001/jama.287.6.742

Winningham, R. G., \& Pike, N. L. (2007). A cognitive intervention to enhance institutionalized older adults' social support networks and decrease loneliness. Aging \& Mental Health, 11(6), 716-721. http://dx.doi.org/10.1080/13607860701366228

Xie, B., \& Bugg, J. M. (2009). Public library computer training for older adults to access high-quality Internet health information, Library \& Information Science Research, 31, 155-162. http://dx.doi.org/10.1016/j.lisr.2009.03.004 